which is produced in a closed plant cell-based system, contained within disposable plastic chambers. New York-based Pfizer's move to in-license-and subsequently acquire-rights to this product outside of Israel and Brazil (where Protalix has entered a technology transfer and supply agreement with the country's health ministry) shows big pharma is at least open to the technology, even if it not yet getting involved in early-stage development.

"That was an important step, I think," says Julian Ma, professor of molecular immunology at St. George's University of London, in the UK. Also significant, he adds, was the production last year of a cocktail of antiEbola virus antibodies from transgenic tobacco. "All of a sudden plant antibodies became known around the world, despite everyone calling them secret serum to begin with," says Ma. Criticism arising from the shortage of the drug was misplaced, he adds. "The miracle was there was enough to treat nine patients, based on the stage of development at that time." Ma led an EU-funded research program that conducted the first clinical trial of a plant-produced monoclonal antibody, a topically applied HIV drug called P2G12, produced by transgenic tobacco. His group is now further refining the production process to generate an intravenous version of the same drug.

Glycosylation patterns in plant-produced proteins can differ from those obtained in mammalian culture systems. They tend to be homogeneous however, whereas mammalian cell production systems generate a wider distribution of glycosylation variants.
"Essentially we got a single glycoform," Ma says. "We don't see it with all antibodies." Greenovation Biotech, of Freiburg, Germany, has engineered the glycosylation machinery of its producing strain of moss, Physcomitrella patens, in order to eliminate plant specific $\alpha$-1,3-fucose and $\beta$-1,2-xylose residues and maximize the numbers of proteins with $\mathrm{N}$-terminal mannose residues, so as to favor uptake by kidney cells (J. Inherit. Metab. Dis. 27 August 2015, doi:10.1007/ s10545-015-9886-9). The company recently obtained clearance to conduct the first trial of a therapeutic produced from this system, $\alpha$-galactosidase A, in patients with Fabry disease (Nat. Biotechnol. 33, 1122, 2015). "The dosing begins in April," says CEO Thomas Frischmuth. "We have to produce two new batches of the enzyme." The company, which, like Protalix, also uses a closed, disposable cell culture system, is at present scaling up production from 300 liters to 5,000 liters. That would be sufficient to cover the world's entire population of patients with Fabry disease. "Our production is now very close to what mammalian cell systems are."

Production systems based on mammalian cell culture continue to set the standard, and alternative systems have failed to keep pace with them over the past two decades. But they are filling niches that conventional systems have failed to address adequately-and the next two decades are unlikely to be a repeat of the last two. As the case of Synageva shows, the opportunity exists. "It's all about getting products out onto the market," Ma says.

Cormac Sheridan Dublin

\title{
Obama's cancer moonshot
}

President Barack Obama in his final year in office is endorsing a nationwide effort to accelerate the testing of immunotherapy drug combinations to fight cancer. The president announced the project-dubbed Cancer MoonShot 2020 —at his last State of the Union address, delivered on January 16. The effort will assemble an Apollo-sized team, known as the National Immunotherapy Coalition (NIC). This will include industry players such as Thousand Oaks, California-based Amgen and Summit, New Jerseybased Celgene, big pharma, and small biotechs like Culver City, California-based NantWorks, as well as oncologists, academic institutions, insurers, and senior officials from the FDA and the National Cancer Institute. Patrick Soon-Shiong, founder and chairman of the group of companies, is the driving force behind the coalition, and Vice President Joe Biden, whose son died of cancer last year, will be leading the moonshot project. The NIC will test more than 60 molecules in different combinations in 20 tumor types. The multitrial initiative aims to enroll 20,000 patients, who will have their whole genomes sequenced and be tested with proteomic diagnostics to match to the appropriate immunotherapies. The coalition could be a boon for the biotech industry, though observers note that Bristol-Myers Squibb, Merck and Roche, those with the most advanced immunotherapies, are already running combination trials with anti-PD-1/PD-L1 therapies, and were absent from the proceedings. 